\title{
Analyses on Prestress Loss and Flexural Performance of the Laminated Bamboo Beam Applied with Prestressed BFRP Sheet
}

\author{
Qingfang Lv, Ye Liu (D), and Yi Ding \\ Key Laboratory of Concrete and Prestressed Concrete Structures of the Ministry of Education, Southeast University, \\ Nanjing 210096, China \\ Correspondence should be addressed to Ye Liu; 459912879@qq.com
}

Received 21 December 2018; Revised 16 March 2019; Accepted 2 April 2019; Published 30 April 2019

Academic Editor: Flora Faleschini

Copyright (c) 2019 Qingfang Lv et al. This is an open access article distributed under the Creative Commons Attribution License, which permits unrestricted use, distribution, and reproduction in any medium, provided the original work is properly cited.

Inspired by the studies about wooden beam applied with prestressed steel plate and bamboo beam strengthened by fiberreinforced polymer (FRP), this paper aims to explore the applicability of the prestressed basalt fiber-reinforced polymer (BFRP) sheet to the laminated bamboo beam and the variation of the flexural performance of the laminated bamboo beam applied with prestressed BFRP sheet. Two series of tests were conducted in the present study. In the first series of tests, the prestress loss of the prestressed BFRP sheet was classified and analyzed based on measured strains and deflections, which led to a derivation of the effective prestressed force considering the prestress loss. Analyses showed that the recommended value of prestress loss compared with the initial prestressed force was $22.0 \%$ based on the existing test data in the specimen preparation stage. In the second series of tests, the static loading test was performed to investigate the flexural performance of the laminated bamboo beam applied with prestressed BFRP sheet and analyze the difference between the laminated bamboo beams applied with prestressed and nonprestressed BFRP sheets. Test results showed that the no significant variation of the ultimate load and a reduction of the ultimate deformation capacity were caused by the application of the prestressed BFRP sheet.

\section{Introduction}

As a traditional structural material [1], the bamboo is convenient to be locally obtained and has usually been utilized in building local houses in China, which has advantages such as saving costs, environmental friendliness, and recyclability [2-4]. In general, the tensile and compressive stresses of the bamboo are twice and 1.5 times than those of wood, respectively, and the strength to weight ratio of the bamboo is higher than wood and steel [5]. However, the mechanical properties of the raw and unprocessed bamboo material are unstable, with large discreteness [6]. Many inevitable defects can also be found in the unprocessed bamboo material, which results in a poor durability [7-9]. To utilize advantages of the raw bamboo and improve its material stability and performance, kinds of bamboo engineering material, including laminated bamboo $[10,11]$ and reconstituted bamboo [12, 13], have been proposed and studied, which is beneficial to reduce the material discreteness and enlarge practical applications of the bamboo [14].

The stiffness-control design is often adopted for the modern bamboo structure [15], which limits the application of the bamboo engineering material. Therefore, to improve the practical utilization of the bamboo engineering material, the strengthening techniques [16-19] are recommended and of important necessity. Adding fibers into the bamboo engineering material during the processing stage can improve the strength of the bamboo engineering material. The mechanism of the fibers enriching the strength of the bamboo strip has been studied [20-22].

Similar to the bamboo, the wood also encounters the difficulties in broadening its application due to the stiffnesscontrol design. As early studied by Peterson [23], the prestressed steel plate was used to strengthen the wooden glulam beam. However, the incompatible elastic moduli of steel and wood resulted in the significant deformation of the wood and large prestress loss. Compared with the steel, the 
elastic modulus of the basalt fiber-reinforced polymer (BFRP) is relatively small [24], which may have a better cooperative working performance with bamboo engineering material [25]. A recent study conducted by Wei et al. showed that the application of the fiber-reinforced polymer (FRP) can be effective in improving the flexural performance of bamboo beams [26].

Inspired by the above studies, this paper explores the application of the prestressed BFRP sheet in the laminated bamboo beam. In order to obtain the reliable performance of the laminated bamboo beam applied with the prestressed BFRP sheet, the prestress loss is firstly investigated. Until now, the standard prestress tensioning method had not been formed, and various prestress loss would be resulted from different tensioning facilities and methods. Based on the prestress tensioning method proposed in this paper, the prestress loss was classified and calculated. Referable studies included the prestress loss in the posttensioned CFRP sheetstrengthened concrete beam [27, 28]. Secondly, the flexural performance of the laminated bamboo beam applied with the prestressed BFRP sheet is studied, which is valuable for the formation of the design of such structure.

\section{Material Properties}

2.1. Material Test on Laminated Bamboo considering Size Effect. The mechanical properties of the bamboo engineering material were found to be related to the dimension of the tested specimen. In order to take the size effect into consideration, one laminated bamboo beam specimen with a dimension $(b \times h \times l)$ of $50 \mathrm{~mm} \times 150 \mathrm{~mm} \times 3000 \mathrm{~mm}$ was tested first, almost the same dimension with the beam used in the laminated bamboo beam applied with prestressed BFRP sheet to be investigated in the following section. Details of the material test specimen are listed in Table 1, and the four-point bending test setup for the material test specimen is depicted in Figure 1.

The flexural modulus, $E_{\mathrm{m}}$, and flexural stress, $f_{\mathrm{m}}$, of the laminated bamboo can be obtained based on

$$
\begin{aligned}
& E_{\mathrm{m}}=\frac{a \Delta F}{48 I \Delta \omega}\left(3 l_{0}^{2}-4 a^{2}\right), \\
& f_{\mathrm{m}}=\frac{a F_{\mathrm{u}} h}{4 I},
\end{aligned}
$$

where $a$ is the distance between the support and loading point; $l_{0}$ is the clear span of the laminated bamboo beam between two supports; $\Delta F$ is the loading increment; $\Delta \omega$ is the deflection increment corresponding to the loading increment; $I$ equal to $b h^{3} / 12$ is the moment of inertia of the laminated bamboo beam, where $b$ and $h$ are the width and height of the laminated bamboo beam, respectively; and $F_{\mathrm{u}}$ is the maximum applied load during the material test. The flexural modulus, $E_{\mathrm{m}}$, and the flexural stress, $f_{\mathrm{m}}$, for the laminated bamboo are calculated and listed in Table 1 based on the material test.

2.2. Material Test on BFRP Sheet. The BFRP sheet with density of $300 \mathrm{~g} / \mathrm{cm}^{2}$ was provided by the Basalt Fiber Center of Southeast University. Six BFRP sheets with a nominal thickness of $0.147 \mathrm{~mm}$ were tested under tension per ACI 440 [29], where the BFRP sheet was impregnated with epoxy resin adhesive L-500. The tensile strength and the flexural strengths of the epoxy resin adhesive L-500 were $48.8 \mathrm{MPa}$ and $77.5 \mathrm{MPa}$, respectively. Failure photos of the six BFRP sheets are shown in Figure 2. Test results showed that the average ultimate tensile strain, elastic modulus, ultimate tensile stress, and standard tensile stress were $2.51 \%$, 73.8 GPa, $1725.4 \mathrm{MPa}$, and 1563.2 MPa. The mechanical behavior of the BFRP sheet was considered as elastic and linear.

The above test on mechanical properties of the BFRP sheet was based on the standard testing specimen. However, the possible variation of mechanical properties of the BFRP sheet with long span and large width is not clear until now, which is of important necessity to be evaluated. One test was thus conducted to assess the tensile performance of two layers of BFRP sheets with a length of $3000 \mathrm{~mm}$ and width of $50 \mathrm{~mm}$ after impregnated with epoxy resin adhesive L-500. The control tensile force was $12.0 \mathrm{kN}$. The strain distributions of the BFRP sheet along the length direction were detected based on three groups of strain gages, and each group is composed of three strain gages, as shown in Figure 3.

The load-strain curve of the two layers of BFRP sheets is shown in Figure 4, where the ordinate of the figure is average strain obtained from strain gages in the group $\mathrm{B}$ attached in the middle of the BFRP sheet. The significant fluctuation can be observed during the loading history due to the manual compression processing of the adhesive. Before the control tensile force, no failure was found in the BFRP sheet. Besides, the strain distributions along the length direction were relatively even based on detected strain variation. The calculated elastic modulus was $72.97 \mathrm{GPa}$ close to that obtained from the standard test specimen, which demonstrated that the long span and large width did not affect the basic mechanical properties of the BFRP sheet.

\section{Preliminary Design for the Laminated Bamboo Beam Applied with Prestressed BFRP Sheet}

3.1. Prestress Control. When the initial prestress was relatively too high for the laminated bamboo beam applied with prestressed BFRP sheet, the following problems may be expected: (1) relatively large initial deflection, (2) relatively large slip between the BFRP sheet and laminated bamboo beam, and (3) the fracture or significant creep of the BFRP sheet under high prestress. When the initial deflection was large, the laminated bamboo beam applied with prestressed BFRP sheet may be in the antiarch state in the normal use state. Therefore, it is of important necessity to determine the appropriate range of the initial prestressed force of the BFRP sheet to avoid the above problems.

The recommended initial deflection caused by the initial prestressed force of the BFRP sheet was defined as $L_{t} / 500$ based on the principle of the initial deflection caused by 
TABLE 1: Material properties of the laminated bamboo considering size effect.

\begin{tabular}{lcccccccc}
\hline Type & $l(\mathrm{~mm})$ & $l_{0}(\mathrm{~mm})$ & $a(\mathrm{~mm})$ & $b(\mathrm{~mm})$ & $c(\mathrm{~mm})$ & $h(\mathrm{~mm})$ & $E_{\mathrm{m}}\left(\mathrm{N} / \mathrm{mm}^{2}\right)$ & $f_{\mathrm{m}}\left(\mathrm{N} / \mathrm{mm}^{2}\right)$ \\
\hline Laminated & 3000 & 2700 & 900 & 50 & 150 & 150 & 11329.5 & 61.2 \\
\hline
\end{tabular}

Note. $l$ is the total length of the material test specimen; $c$ is the distance between the end of the beam and support, which is set to avoid the stress concentration at the corner of the laminated beam.

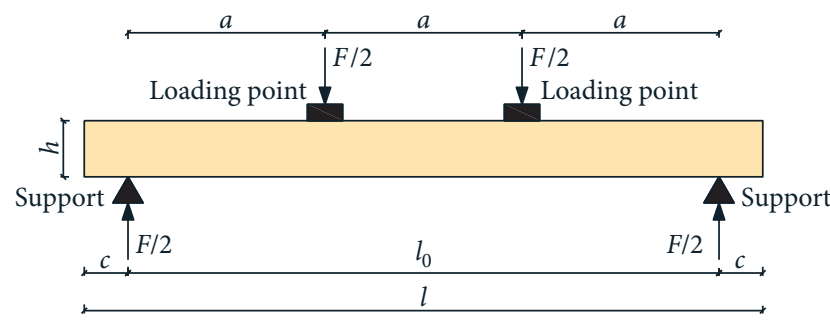

Figure 1: Material test setup.

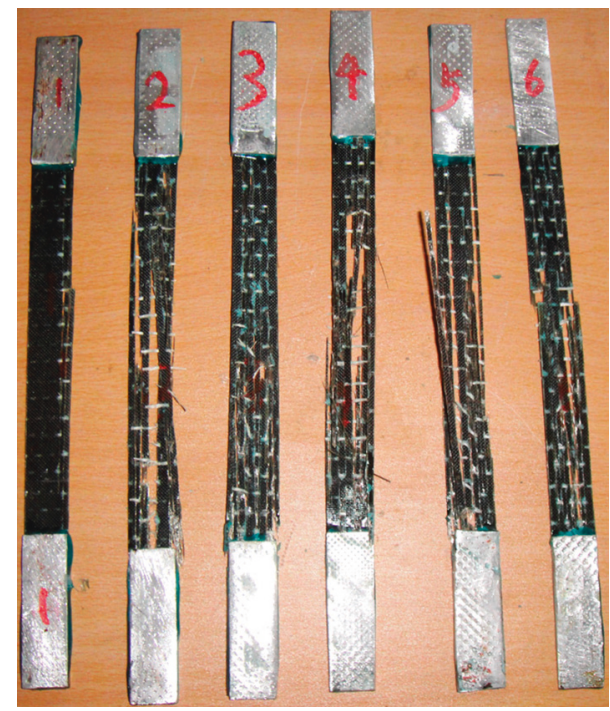

FIGURE 2: Failure photos of BFRP sheets under standard tension testing.

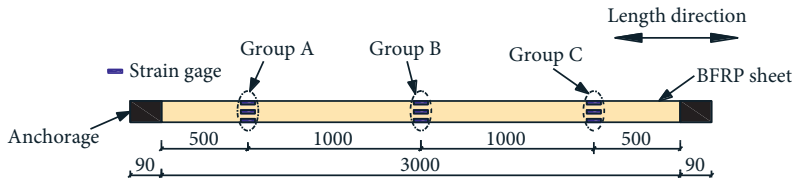

FIgURE 3: Layout of strain gages for BFRP sheets with long span and large width.

initial prestressed force equal to the deflection resulted from the dead load, where the dead load was taken as $0.15 \mathrm{kN} / \mathrm{m}^{2}$ and $L_{\mathrm{t}}$ is the total length of the laminated bamboo beam. For a certain initial prestress level, the calculated initial deflection can be compared with the recommended initial deflection, $L_{t} / 500$, to determine whether the initial prestress level is appropriate. When the prestress loss was neglected and the elastic state of the laminated bamboo beam was assumed, the initial antiarch value, $\omega_{\mathrm{i}}$, caused by the initial prestressed force can be calculated as expressed in equation

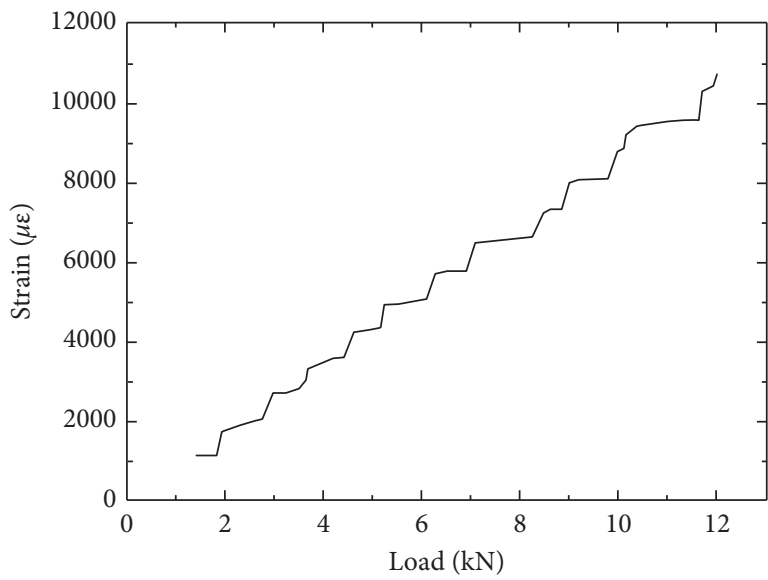

FIGURE 4: Load-average strain curve obtained from strain gages in group $B$.

(2), where the contribution of the BFRP sheet to the moment of inertia is not considered because the BFRP sheet is in the compressive zone.

$$
\omega_{\mathrm{i}}=\frac{M_{\mathrm{i}} L_{t}^{2}}{8 E_{\mathrm{m}} I},
$$

where $M_{\mathrm{i}}$ is the initial moment caused by the initial prestressed force and is expressed in the following equation:

$$
M=\frac{f_{\mathrm{i}} A h}{2},
$$

where $f_{\mathrm{i}}$ is the initial prestress level and $A$ is the cross section area of the BFRP sheets and is $2 \times 0.147 \mathrm{~mm} \times 50 \mathrm{~mm}$ for two layers of BFRP sheets with nominal thickness of $0.147 \mathrm{~mm}$ and width of $50 \mathrm{~mm}$.

When the initial prestress level is 35\% of the standard tensile stress of the BFRP sheet, $f_{\mathrm{tk}}$, the calculated initial antiarch value is $4.1 \mathrm{~mm}$ less than $L_{t} / 500$. When the initial prestress level is $0.50 f_{\mathrm{tk}}$, the calculated initial antiarch value is $5.9 \mathrm{~mm}$ almost reaching $L_{t} / 500$. Therefore, the value of the initial prestress is defined as $0.50 f_{\text {tk }}(11.49 \mathrm{kN}, 781.6 \mathrm{MPa})$ in this paper. To compensate for the prestress loss, a $5 \%$ super tension is adopted, which finally leads to a recommended initial prestressed force of the BFRP sheet of $12.0 \mathrm{kN}$.

3.2. Bond Slip Verification. The bond slip between the BFRP sheet and the laminated bamboo should be checked to confirm the reliability of the employment of the prestressed BFRP sheet to the laminated bamboo beam when the bonding material is adopted as the epoxy resin adhesive L-500. Based on test results of a series of double shear tests on the bond behavior between the two-layer BFRP sheets 
and laminated bamboo (width of $50 \mathrm{~mm}$ and bond length of $300 \mathrm{~mm}$ ) listed in Table 2, it is found that the average ultimate bond strength $(36.7 \mathrm{kN})$ is far more than the recommended initial prestressed force $(12.0 \mathrm{kN})$ [30]. The strain variation of the BFRP sheet is limited within the $100 \mathrm{~mm}$ range away from the loaded end. It is found that the bond slip value caused by the initial prestressed force is small, which is calculated as $0.08 \mathrm{~mm}$ under a force of $12 \mathrm{kN}$.

\section{Specimen Preparation}

The main process of the preparation for the laminated bamboo beam applied with prestressed BFRP sheet is summarized as follows:

(1) Impregnating and interfacial treatment: Two layers of BFRP sheets were impregnated with epoxy resin adhesive L-500. For ease of applying the initial prestress force to the BFRP sheet, a special fixture which was composed of two steel plates with two bolt holes shown in Figure 5(a) was introduced after 2day cure of the epoxy resin adhesive L-500. When the special fixture was connected to the end of the BFRP sheet, the prestressed force applied by the tensioning equipment can be exerted to the special fixture and then transferred to the BFRP sheet. Besides, the plum blossom notches were made on the surface of the laminated bamboo beam to increase the bond between the BFRP sheet and laminated bamboo beam.

(2) Applying prestressed force: Firstly, both of the BFRP sheet and surface of the laminated bamboo beam were coated with the structural adhesive and then pressed together. Then, graded prestressed forces, including four force levels of $5 \mathrm{kN}, 8 \mathrm{kN}, 19 \mathrm{kN}$, and $11.49 \mathrm{kN}$ (or $12.0 \mathrm{kN}$ ), were applied to the BFRP sheet. The load holding duration for each level of prestressed force was about 2 minutes, and the BFRP sheet was pressed to make the distribution of the structural adhesive even during the holding duration.

(3) Releasing BFRP sheet: Both ends of the laminated bamboo beam were constructed with the structural measurement shown in Figure 5(b), which was characteristic as two steel plates connected by four bolts and aimed at avoiding the delamination between the BFRP sheet and laminated bamboo beam due to the shear stress and normal stress [31, 32]. After 7-day curing of the epoxy resin adhesive L-500, the BFRP sheet between the beam end and tensioning equipment was cut, which meant that the BFRP sheet was released and the prestressing was finished. The representative specimen of the laminated bamboo beam applied with prestressed BFRP sheet after completion is shown in Figure 6.

In the present study, the whole tensioning system at the tensioned and fixed ends is depicted in Figure 7. Nine components were involved in this system, which were independent reaction system, special fixture for BFRP sheet,
TABLE 2: Test results of double shear test.

\begin{tabular}{lcc}
\hline Specimen label & Bonding material & Ultimate load $P_{\mathrm{u}}$ \\
\hline JQ1 & L-500 & $36.5 \mathrm{kN}$ \\
JQ2 & L-500 & $38.5 \mathrm{kN}$ \\
JQ3 & L-500 & $35.0 \mathrm{kN}$ \\
\hline
\end{tabular}

tensioning fixture, reaction cylinder, anchor bolt, bearing plate, center hole jack, anchor nut, and force transducer. The anchor nut was used to keep the jack in place at the tensioned end and fasten the tensioning fixture at the fixed end. When the applied force reached the target initial prestressed force, the anchor bolt depicted in Figure 7(a) would be fixed in order to dismount the center hole jack.

\section{Prestress Loss in the Laminated Bamboo Beam Applied with Prestressed BFRP Sheet}

5.1. Definition of Prestress Loss. Taking the release of the prestressed BFRP sheet as a dividing line, the specimen can be divided into preparation stage and storage stage. The former is defined as the preparation process of the specimen until the release of the BFRP sheet and the latter is recognized as the specimen to be stored or used after the release. Based on different stages, types of the prestress loss observed in the laminated bamboo beam applied with prestressed BFRP sheet are summarized as follows.

In specimen preparation stage, (1) $\sigma_{l 1}$ was caused by the deformation of the tensioning equipment and the bond slip between the tensioning fixture and BFRP sheet; (2) $\sigma_{l 2}$ was caused by the retraction of the BFRP sheet due to tightening of the anchor bolt; (3) $\sigma_{l 3}$ was caused by the friction between the BFRP sheet and laminated bamboo beam; (4) $\sigma_{l 4}$ was caused by the relaxation of the BFRP sheet after reaching the target initial prestressed force and before the release of the BFRP sheet; (5) $\sigma_{l 5}$ was caused by the elastic deformation of the laminated bamboo beam at the time of the release of BFRP sheet; and (6) $\sigma_{l 6}$ was caused by the bond slip between the BFRP sheet and laminated bamboo beam due to the release of the BFRP sheet.

In specimen storage stage, (1) $\sigma_{l 4}$ was caused by the further relaxation of the BFRP sheet after releasing of the BFRP sheet; (2) $\sigma_{l 7}$ was caused by the creep of the structural adhesive; and (3) $\sigma_{l 8}$ was caused by the creep of the laminated bamboo beam.

5.2. Measurement of Prestress Loss. In order to quantitatively measure the prestress loss in the laminated bamboo beam applied with prestressed BFRP sheet, three specimens including P-1, P-2, and P-3 were tested in this section, details of which are listed in Table 3. Specimen P-1 without structural measurement in Figure 5(b) was monitored at the preparation stage, and specimens P-2 and P-3 with structural measurement were tested until the storage state. The strains of the BFRP sheet and loads at tensioned and fixed ends during the preparation and storage stages were monitored by strain gages shown in Figure 8 and force 


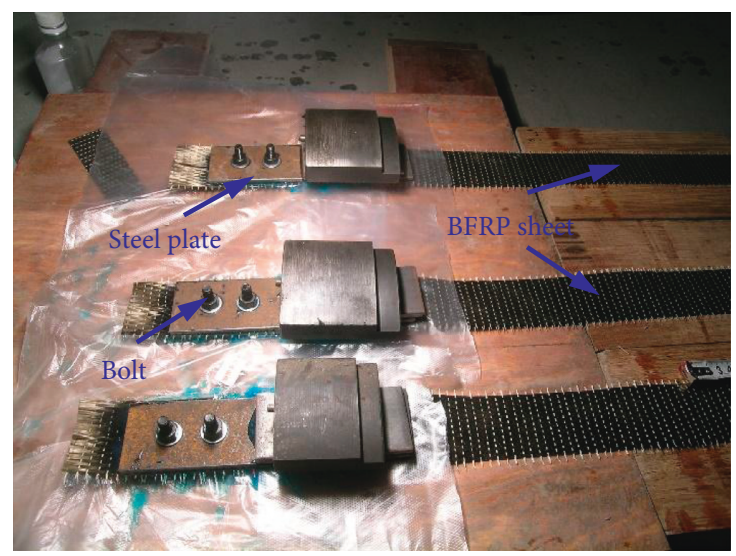

(a)

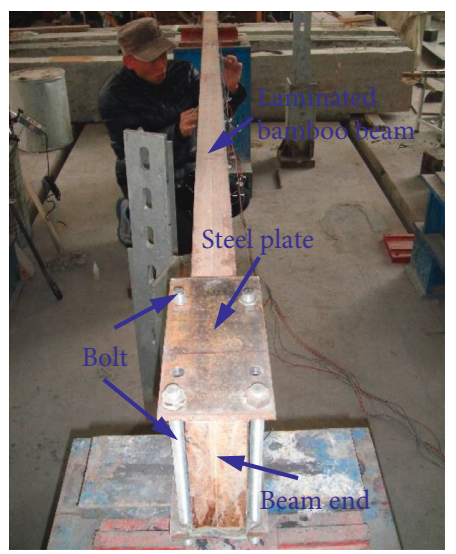

(b)

FIGURE 5: Specimen preparation: (a) special fixture for BFRP sheet and (b) structural measurement.

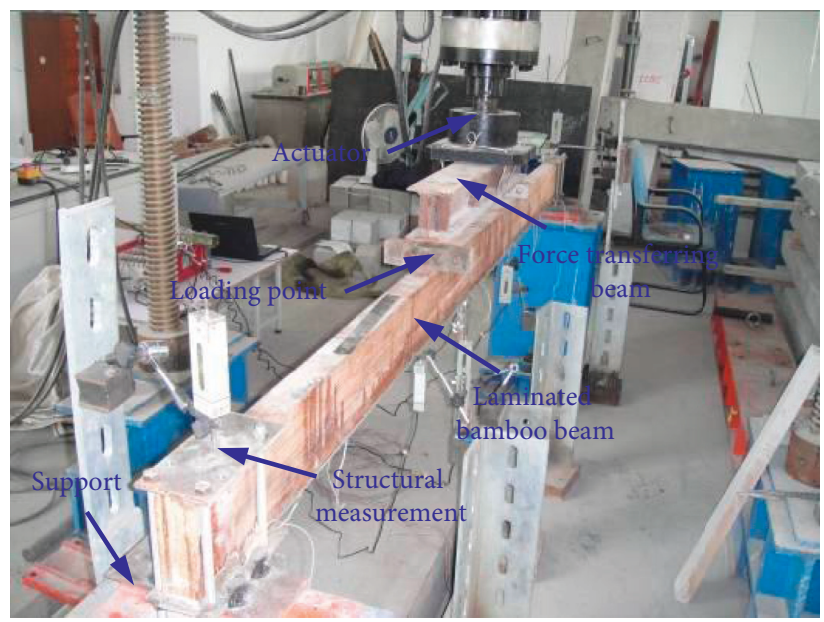

FIGURE 6: The photo of the laminated bamboo beam applied with prestressed BFRP sheet.

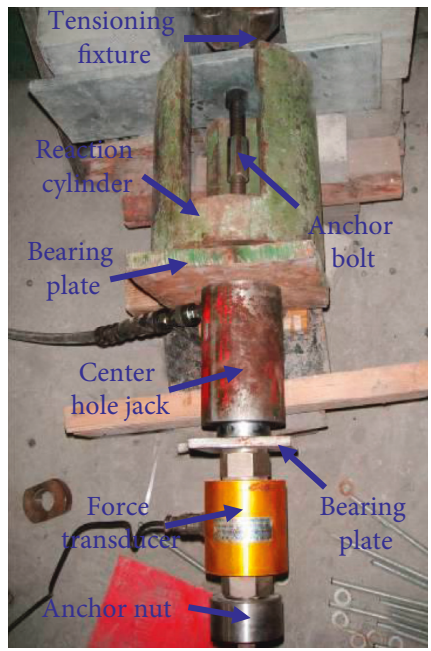

(a)

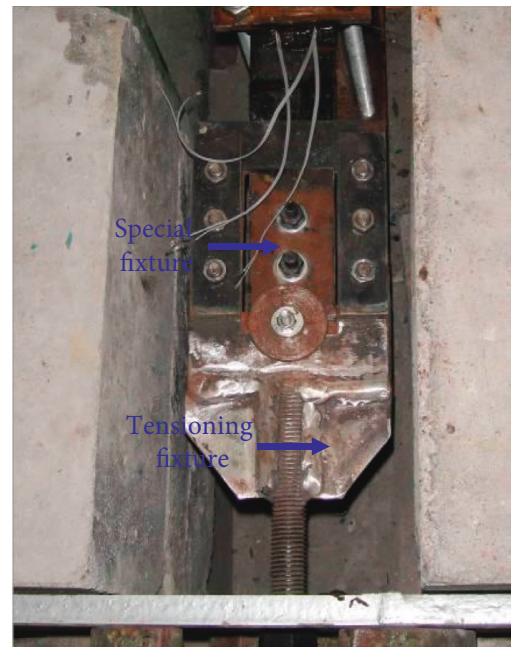

(b)

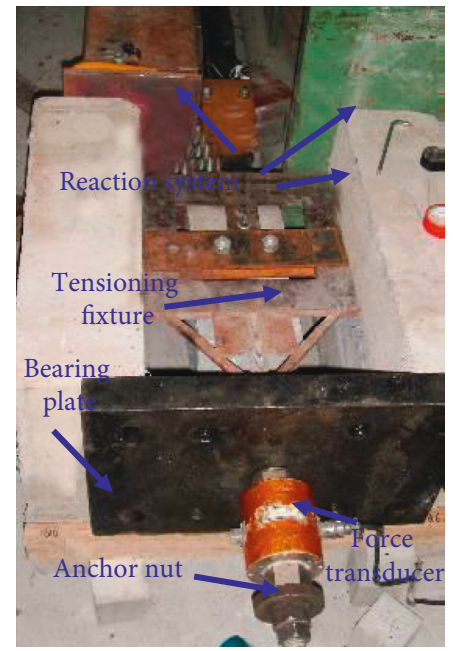

(c)

Figure 7: Assembly of tensioning system: (a) tensioned end, (b) tension fixture, and (c) fixed end. 
TABLE 3: Specimens for measuring the prestress loss.

\begin{tabular}{llccccc}
\hline Label & $b \times h \times l(\mathrm{~mm})$ & $F_{0}(\mathrm{kN})$ & $b_{\mathrm{f}}(\mathrm{mm})$ & $\varepsilon_{0}$ & Preparation stage & Storage stage \\
\hline P-1 & $50 \times 150 \times 2978$ & 12.02 & 51.2 & 10820 & $2-911: 38$ to 2-13 9:09 & - \\
P-2 & $50 \times 150 \times 2978$ & 12.54 & 51.9 & 11135 & $2-1810: 45$ to 2-24 9:08 & $2-249: 08$ to 3-03 8:11 \\
P-3 & $50 \times 150 \times 3000$ & 12.54 & 51.1 & 11310 & $3-0311: 35$ to 3-10 8:55 & $3-108: 55$ to 3-14 8:55 \\
\hline
\end{tabular}

Note. $F_{0}$ is the actual load applied at the tensioned end, which is the target initial prestressed force; $b_{\mathrm{f}}$ is the width of the BFRP sheet; $\varepsilon_{0}$ is the calculated initial strain caused by the initial prestressed force; 2-9 11:38 means the data were monitored at $11: 38$ on February 9.

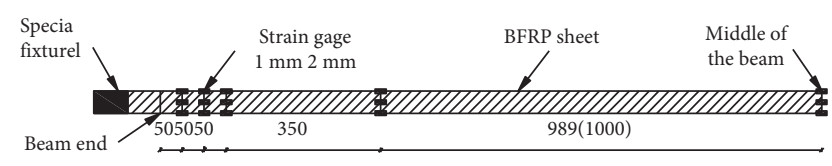

FIGURE 8: Strain gages for specimens P-1, P-2, and P-3 (the number in brackets is adopted for specimen $\mathrm{P}-3$ ).

transducers depicted in Figure 7, respectively. The deflections of the specimens were also measured.

5.3. Test Results of Prestress Loss. The measured values related to the prestress loss in the three specimens are listed in Table 4. Symbols in Table 4 are explained as follows: $F^{\prime}$ is the measured load at the fixed end caused by $F_{0} ; F_{\min }^{\prime}$ is the measured load at the fixed end before releasing the BFRP sheet; and $\varepsilon_{0}^{\prime}$ is the midspan initial strain caused by the initial prestressed force, which was the average value of strains of the BFRP sheet obtained from three strain gages at the midspan. The measured values of $\varepsilon_{0}^{\prime}$ agreed well with calculated values of $\varepsilon_{0} ; \varepsilon_{1}^{\prime}$ is the midspan strain of the BFRP sheet before the release of the BFRP sheet; $\varepsilon_{2}^{\prime}$ is the midspan strain of the BFRP sheet after the release of the BFRP sheet; $\varepsilon_{3}^{\prime}$ is the midspan strain of the BFRP sheet until the end of measurement of the storage stage; and $\omega_{0}$ is the theoretical initial deflection caused by $F_{0}$, based on equation (2). Considering the effect of the structural measurement employed in specimens P-2 and P-3, ends of the two specimens were viewed as rigid, which were removed from the total length of the specimen in the calculation of $\omega_{0} ; \omega^{\prime}$ is the deflection after the release of the BFRP sheet; $\omega_{\max }^{\prime}$ is the final deflection until the end of measurement of the storage stage.

\subsection{Quantitative Prestress Loss Analyses}

5.4.1. Prestress Loss in the Preparation Stage. The calculation of different types of prestress losses was conducted based on the preparation stage and storage stage, respectively. Firstly, the prestress losses occurred in the preparation stage were analyzed. In the present test, the interface between the tensioning fixture and BFRP sheet was rough and the tensioning equipment was rigid enough, which made the prestress loss $\sigma_{l 1}$ small enough to be neglected. Both of the prestress losses $\sigma_{l 2}$ and $\sigma_{l 3}$ can be calculated by the difference between $F^{\prime}$ and $F_{0}$ after the completion of tensioning, which were $0.24 \mathrm{kN}, 0.52 \mathrm{kN}$, and $0.46 \mathrm{kN}$ for specimens $\mathrm{P}-1, \mathrm{P}-2$, and $\mathrm{P}-3$, respectively. The ratios of the prestress losses $\sigma_{l 2}$ and $\sigma_{l 3}$ of the three specimens to the applied load at the tensioned end, $F_{0}$, were $2.0 \%, 4.1 \%$, and $3.7 \%$, respectively.
After reaching the target initial prestressed force and before the release of the BFRP sheet, the prestress loss $\sigma_{l 4}$ can be calculated by monitoring the load variation at the fixed end, as shown in Figure 9. It is concluded that the prestress relaxation developed quickly at the initial stage. After 20 hours, the load variation caused by the prestress relaxation gradually became gentle. The prestress loss caused by the BFRP sheet relaxation and the ratio of the certain relaxation to the total relaxation under a certain period are listed Table 5. It can be found that the prestress loss $\sigma_{l 4}$ caused by the relaxation of the BFRP sheet in the preparation stage was $10.0 \%$ to $15.6 \%$ of the applied load at the tensioned end $F_{0}$ based on load variation. Within 2 hours, the prestress loss was about $30 \%$ of the total loss, and the prestress loss within 20 hours was around $50 \%$ to $70 \%$ of the total loss. Until 40 hours, the prestress loss reached almost $90 \%$ of the total prestress loss. The value of the prestress loss $\sigma_{l 4}$ caused by the relaxation of the BFRP sheet in the preparation stage was related to the initial prestressed stress of the BFRP sheet, which explained that the prestress losses $\sigma_{l 4}$ of specimens P-2 and P-3 with same structural measurement and similar initial prestressed stresses were similar. However, specimen P-1 without structural measurement had relatively larger prestress loss compared with other two specimens.

When the prestressed BFRP sheet was released, both flexural and compressive deformations would result in the prestress loss $\sigma_{l 5}$ of the specimen. In the present study, the flexural and compressive deformations were considered together based on the measurement of the strain variation of the BFRP sheet at the midspan and deflection of the laminated bamboo beam. As listed in Table 4, the values of strain reduction of the BFRP sheet at the midspan equal to $\left(\varepsilon_{1}^{\prime}-\varepsilon_{2}^{\prime}\right)$ caused by the deformations of the laminated bamboo beam were $466 \mu \varepsilon, 664 \mu \varepsilon$, and $592 \mu \varepsilon$ after the release of the BFRP sheet in specimens $\mathrm{P}-1, \mathrm{P}-2$, and $\mathrm{P}-3$, respectively. In specimen P-1 without structural measurement, the prestress loss $\sigma_{l 5}$ was $4.5 \%$ of the measured initial prestressed strain, $\varepsilon_{0}^{\prime}$, while in specimens $\mathrm{P}-2$ and P-3, the prestress loss $\sigma_{l 5}$ reached $5.9 \%$ to $6.8 \%$ of the measured initial prestressed strain, $\varepsilon_{0}^{\prime}$. Until now, the total prestress losses after releasing the BFRP sheet $\left(\sigma_{l 1}+\sigma_{l 2}+\sigma_{l 3}+\sigma_{l 4}+\sigma_{l 5}\right)$ for specimens P-2 and P-3 were $22.2 \%$ and $20.5 \%$, respectively. Furthermore, in terms of the deflection of the laminated bamboo beam, the total prestress losses after releasing the BFRP sheet calculated as $\left(\omega_{0}-\omega^{\prime}\right) / \omega_{0}$ for specimens P-2 and P-3 were $33.0 \%$ and $23.6 \%$, respectively, which agreed well with the above analyses.

The prestress loss $\sigma_{l 6}$ in specimen P-1 without structural measurement was analyzed by the strain distribution along the laminated bamboo beam shown in Figure 10. The 
TABLE 4: Measured results related to prestress loss.

\begin{tabular}{lccccccccc}
\hline Label & $F^{\prime}(\mathrm{kN})$ & $F_{\min }^{\prime}(\mathrm{kN})$ & $\varepsilon_{0}^{\prime}(\mu \varepsilon)$ & $\varepsilon_{1}^{\prime}(\mu \varepsilon)$ & $\varepsilon_{2}^{\prime}(\mu \varepsilon)$ & $\varepsilon_{3}^{\prime}(\mu \varepsilon)$ & $\omega_{0}(\mathrm{~mm})$ & $\omega^{\prime}(\mathrm{mm})$ & $\omega_{\text {max }}^{\prime}(\mathrm{mm})$ \\
\hline P-1 & 11.78 & 9.90 & 10288 & 9519 & 9053 & - & 6.29 & - \\
P-2 & 12.02 & 10.49 & 9811 & 8113 & 7449 & 5991 & 4.54 & 3.04 & 4.15 \\
P-3 & 12.08 & 10.82 & 10093 & 8916 & 8324 & 8108 & 4.62 & 3.53 \\
\hline
\end{tabular}

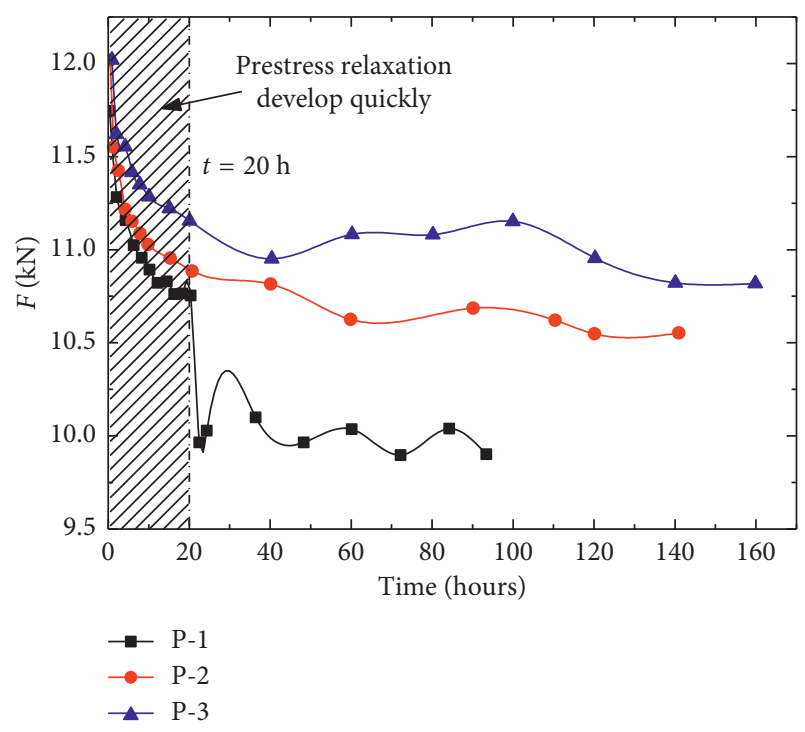

Figure 9: Load variation at the fixed end.

TABLE 5: Calculations for prestress loss $\sigma_{l 4}$.

\begin{tabular}{cccccc}
\hline & $F_{\mathrm{R}}(\mathrm{kN})$ & $\eta_{\mathrm{f}}(\%)$ & $\eta_{\mathrm{F} 2 \mathrm{~h}}(\%)$ & $\eta_{\mathrm{F} 20 \mathrm{~h}}(\%)$ & $\eta_{\mathrm{F} 40 \mathrm{~h}}(\%)$ \\
\hline P-1 & 1.88 & 15.6 & 24.6 & 52.6 & 91.3 \\
$\mathrm{P}-2$ & 1.53 & 12.2 & 30.1 & 73.2 & 77.3 \\
$\mathrm{P}-3$ & 1.26 & 10.0 & 30.9 & 68.3 & 85.0 \\
\hline
\end{tabular}

Note. $F_{\mathrm{R}}$ equal to $\left(F^{\prime}-F_{\min }^{\prime}\right)$ is the load reduction value after reaching the target initial prestressed force and before the release of the BFRP sheet; $\eta_{\mathrm{f}}$ is the ratio of load reduction to the control prestressed force $F_{0} ; \eta_{\mathrm{F} 2 \mathrm{~h}}, \eta_{\mathrm{F} 2 \mathrm{Oh}}$, and $\eta_{\mathrm{F} 40 \mathrm{~h}}$ are the ratios of the load reduction after 2 hours, 20 hours, and 40 hours to $F_{\mathrm{R}}$, respectively.

prestress loss $\sigma_{l 6}$ concentrated within $100 \mathrm{~mm}$ away from the end of the specimen and then minimized quickly, which agreed well with the result obtained in Section 3.2. The large prestress loss at both ends due to the bond slip was observed in specimen P-1. However, due to the existence of the structural measurement at both ends in specimens P-2 and $\mathrm{P}-3$, the strain variation due to the bond slip can be neglected, which means the prestress loss $\sigma_{l 6}$ was neglected in the specimen with structural measurement.

5.4.2. Prestress Loss in the Storage Stage. The further prestress loss can be caused by the creep of the structural adhesive and laminated bamboo beam, as well as the further relaxation of the BFRP sheet after release. Among the three factors, the creep is main reason for the prestress loss. As shown in Figure 11(a), the strain variation of the BFRP sheet at the midspan was monitored in the storage stage. It can be found that the strain variation in specimen P-2 was around

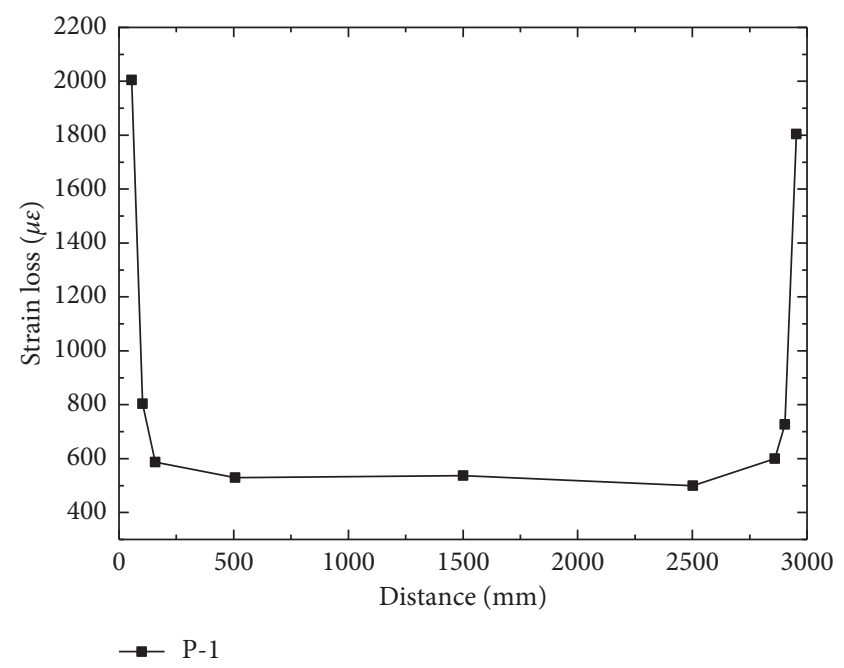

Figure 10: Strain distribution of specimen P-1 for $\sigma_{l 6}$.

$1458 \mu \varepsilon$ and in specimen P-3 was about $216 \mu \varepsilon$. The strain variation of the specimen P-2 became gentle after 100 hours of the release and the strain variation of the specimen P-3 was relatively stale after release. By comparing the strain variation and the measured initial prestressed strain, the prestress losses of specimens P-2 and P-3 were $14.9 \%$ and $2.1 \%$, respectively.

In Figure 11(b), the midspan deflection variation is presented. A significant increase of the midspan deflection in specimen P-2 was observed, which developed from $3.04 \mathrm{~mm}$ to $4.15 \mathrm{~mm}$ as listed in Table 4 . After 100 hours of the release, the deflection of the beam became stable. However, the midspan deflection variation of the specimen P-3 was stable after about 20 hours of the release, and the deflection only grew from $3.53 \mathrm{~mm}$ to $3.77 \mathrm{~mm}$. Test results are relatively dispersed, which means that more measured data are required in the future study pointing at the prestress loss in the storage stage.

5.5. Effective Prestressed Force. The effective prestress, $\sigma_{\text {pe }}$, can be achieved by subtracting the prestress loss, $\sigma_{l}$, from the target initial prestressed force, $\sigma_{\text {con }}$, which is specified in the following equation:

$$
\sigma_{\mathrm{pe}}=\sigma_{\mathrm{con}}-\sigma_{l},
$$

where $\sigma_{l}$ includes $\sigma_{l 1}, \sigma_{l 2}, \sigma_{l 3}, \sigma_{l 4}, \sigma_{l 5}$, and $\sigma_{l 6}$ in the preparation stage and consists of $\sigma_{l 1}, \sigma_{l 2}, \sigma_{l 3}, \sigma_{l 4}, \sigma_{l 5}, \sigma_{l 6}, \sigma_{l 7}$, and $\sigma_{l 8}$ in the storage stage. Based on analyses of prestress loss above, $\sigma_{l}$ in the preparation stage is recommended as $22.0 \%$. However, in the storage stage, due to lack of enough 


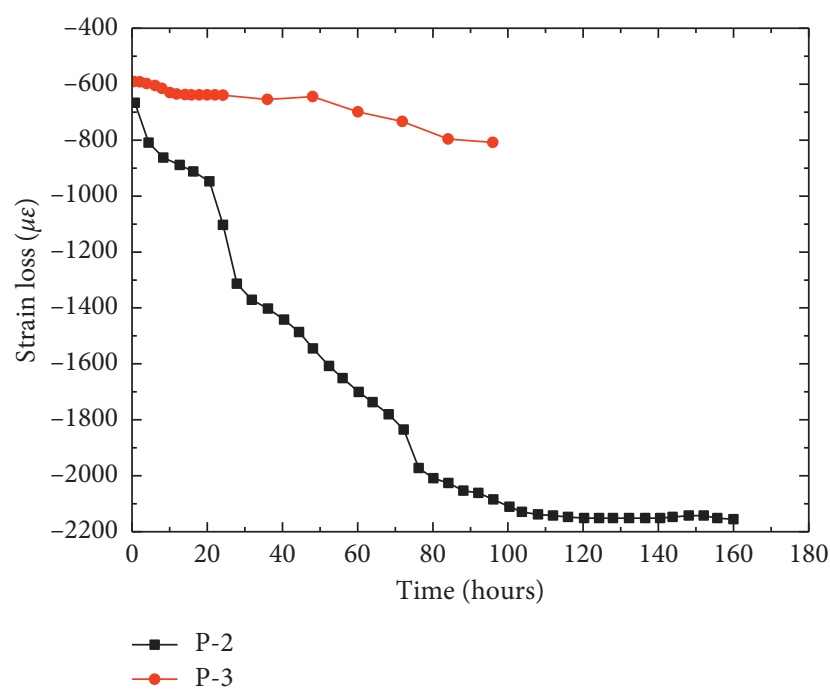

(a)

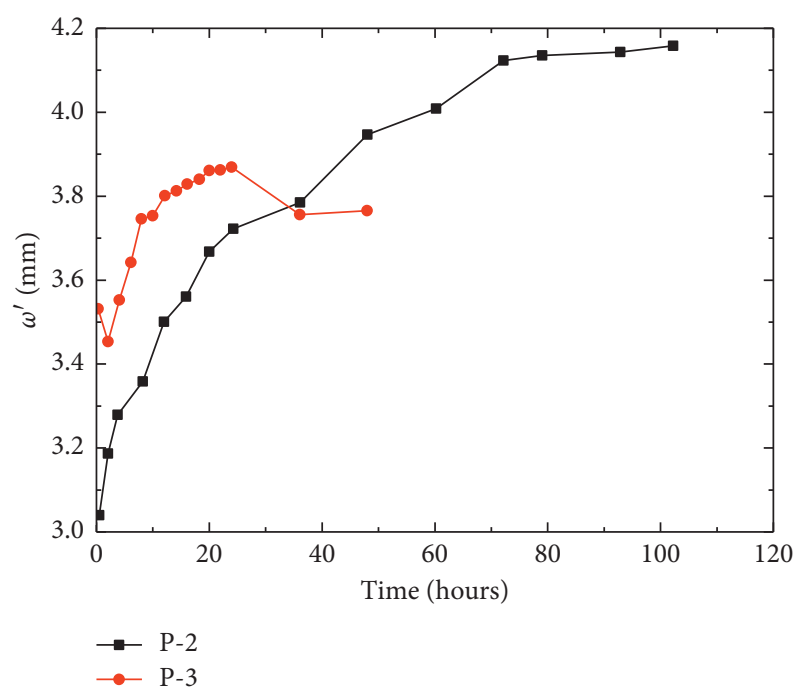

(b)

Figure 11: (a) Strain variation of specimens P-2 and P-3; (b) deflection variation of specimens P-2 and P-3.

calibrated data, the recommended value of prestress loss is not available.

\section{Flexural Performance of the Laminated Bamboo Beam Applied with Prestressed BFRP Sheet}

6.1. Test Protocol. Details of all tested laminated bamboo beams applied with prestressed BFRP sheet are listed in Table 6. The height of the laminated bamboo beam is defined as the nominal height of the laminated bamboo beams applied with prestressed BFRP sheet, and the actual height is defined as the sum of the laminated bamboo beam height, thickness of the BFRP sheet, and thickness of the structural adhesive. The thickness of the structural adhesive was about 2-4 $\mathrm{mm}$, and the thickness of the two layers of BFRP sheets after impregnated with epoxy resin adhesive L-500 was around $1.3 \mathrm{~mm}$. In specimen $\mathrm{B}-1$, the laminated bamboo beam was applied with non-prestressed BFRP sheet, while in specimens B-2 and B-3, the laminated bamboo beam was applied with prestressed BFRP sheet, aiming at investigating the mechanical mechanism related to prestress. Based on analyses of prestress loss above, all specimens were installed with structural measurement at beams' ends. Besides, all specimens were tested shortly after the completion of the prestress tensioning, which meant that the creep of the structural adhesive, laminated bamboo beam, and further relaxation of the BFRP sheet were not taken into consideration for specimens B-2 and B-3.

The four-point bending test was adopted in the present experimental protocol shown in Figure 12, where a $2 \mathrm{kN}$ preload was applied to the specimen to verify the workability of the equipment, and then the specimen was loaded at a loading rate of $3 \mathrm{kN} / \mathrm{min}$ until failure. The layout of the strain gages and displacement transducers is shown in Figure 12. The measurement of the strain and deflection was taken after the completion of the prestressed tension. All data were automatically collected by TDS 530 .

\subsection{Test Results and Discussions}

6.2.1. Experimental Observations. The failure pictures of the laminated bamboo beam applied with non-prestressed or prestressed BFRP sheet are shown in Figure 13. At the initial loading stage, no significant change can be observed in all specimens. The deflection increased distinctly after the proportional limit, and the obviously downward deformation was observed with the further increase of the applied load. When the specimen reached the ultimate load, the BFRP sheet and the bottom fibers of the laminated bamboo beam simultaneously fractured with an abrupt noise. As shown in Figure 13, the failure of the laminated bamboo beam applied with non-prestressed or prestressed BFRP sheet initiated from the loading point and propagated to a certain distance of the laminated bamboo beam.

6.2.2. Load-Deflection Relationship. The load-deflection curves of specimens B-1, B-2, and B-3 are shown in Figure 14, where the initial deflection caused by the prestressed force was subtracted from the measured deflection. The deflection at the midspan reached around $90 \mathrm{~mm}$ to $130 \mathrm{~mm}$ until failure, the ratio of which to $l_{0}$ was about $1 / 30$ to $1.4 / 30$. It can be seen that the laminated bamboo beams applied with both non-prestressed BFRP sheet and prestressed BFRP sheet had good deformation capacity, which promised a good energy dissipation ability in all specimens.

The ultimate loads of the three specimens were $29.5 \mathrm{kN}$, $29.0 \mathrm{kN}$, and $29.5 \mathrm{kN}$, respectively, which meant that the application of the prestressed force in the BFRP sheet did not affect the ultimate load. Until the failure point, the ultimate midspan deflections of specimens B-1, B-2, and B-3 were $131.41 \mathrm{~mm}, 96.41$, and $96.41 \mathrm{~mm}$, respectively. It is 
TABLe 6: Details of tested laminated bamboo beams applied with prestressed BFRP sheet.

\begin{tabular}{|c|c|c|c|c|c|c|c|}
\hline Specimen label & $b \times h \times l(\mathrm{~mm})$ & $l_{0}(\mathrm{~mm})$ & $F_{0}(\mathrm{kN})$ & $b_{\mathrm{f}}(\mathrm{mm})$ & $\sigma_{0}(\mathrm{MPa})$ & $\sigma_{\mathrm{pe}}(\mathrm{MPa})$ & $\omega^{\prime}(\mathrm{mm})$ \\
\hline B-1 & $50 \times 150 \times 3000$ & 2700 & 0 & 51.3 & 0 & 0 & 0 \\
\hline B-2 & $50 \times 150 \times 2978$ & 2700 & 12.54 & 51.9 & 821.8 & 641.0 & 3.04 \\
\hline B-3 & $50 \times 150 \times 3000$ & 2700 & 12.54 & 51.1 & 836.7 & 652.6 & 3.53 \\
\hline
\end{tabular}

Note. $l_{0}$ is the distance between two supports; $F_{0}$ is the actual applied prestressed force; $b_{\mathrm{f}}$ is width of $o$ BFRP sheet; $\sigma_{0}$ is the initial prestressed stress of the BFRP sheet, which is recognized as the target initial prestressed stress, $\sigma_{\text {con }} ; \sigma_{\mathrm{pe}}$ is the effective prestress based on equation (4); $\omega^{\prime}$ is the measured initial deflection caused by the initial prestressed force after release of the BFRP sheet.
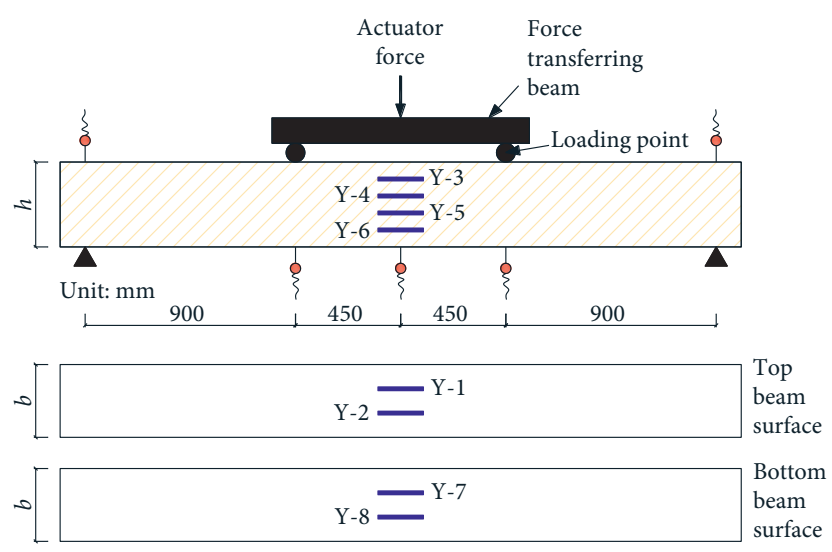

wo- Displacement transducer

Strain gage

FIgURE 12: Test setup and layout of strain gages and displacement transducers.

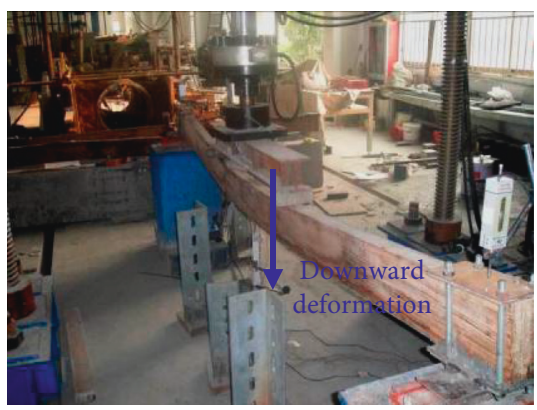

(a)

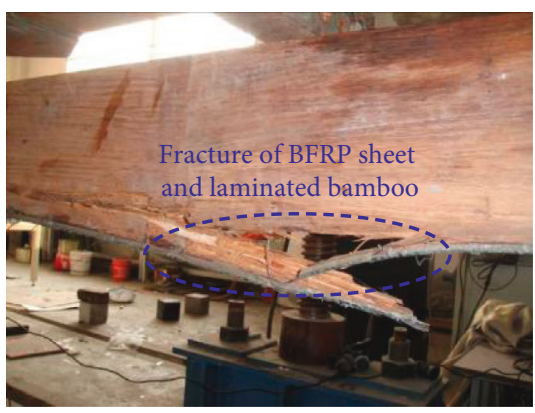

(d)

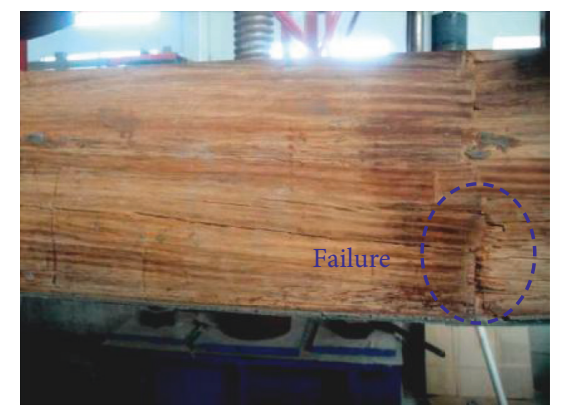

(b)

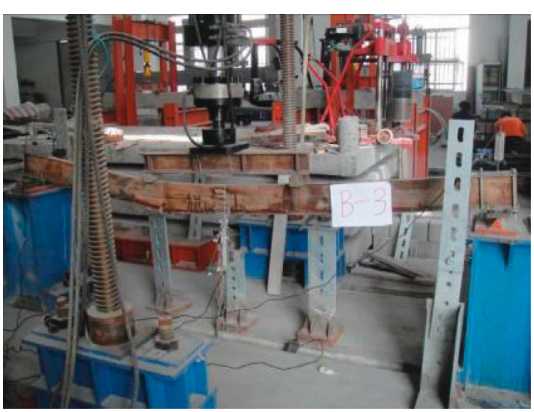

(e)

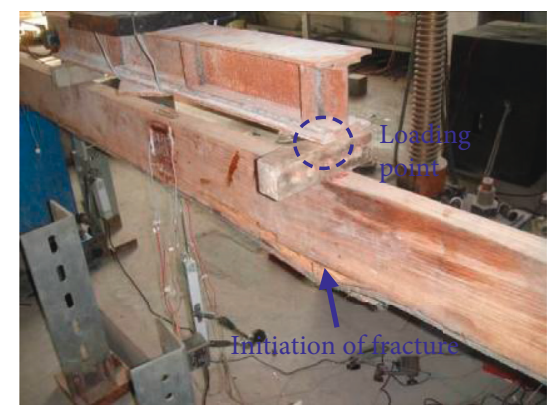

(c)

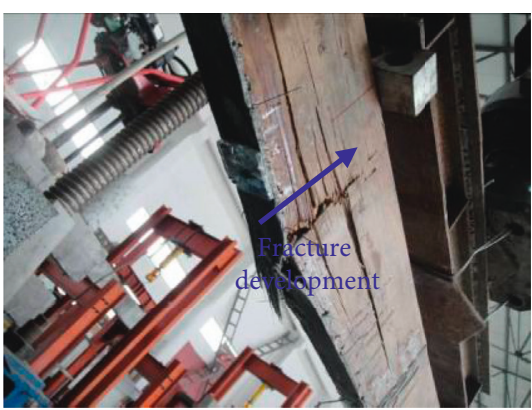

(f)

FIGURE 13: Failure photos of (a) overall and (b) local views for specimen B-1, (c) overall and (d) local views for specimen B-2, and (e) overall and (f) local views for specimen B-3.

demonstrated that the ultimate deformation capacity of the laminated bamboo beam applied with prestressed BFRP sheet was reduced compared with that applied with nonprestressed BFRP sheet.
As shown in Figure 14, the stiffness of the three specimens was almost the same in the linear stage, but the stiffness of the laminated bamboo beam applied with prestressed BFRP sheet was relatively increased compared with 


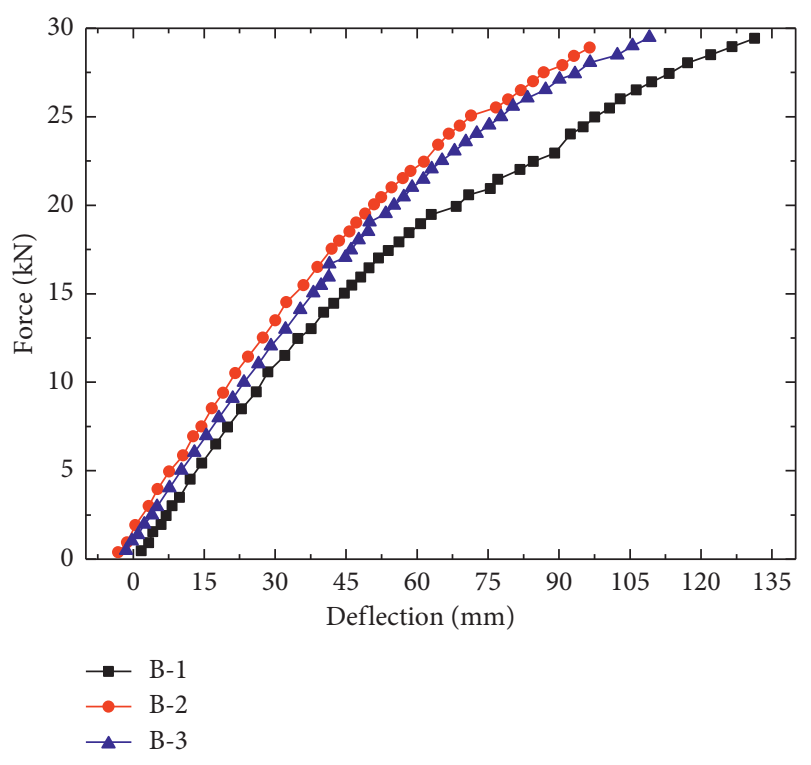

Figure 14: Load-deflection curves at the midspan.

specimen with non-prestressed BFRP sheet after the linear stage. It is found in Figure 15 that at the same applied load, the deflection of the laminated bamboo beams applied with prestressed BFRP sheet (specimens B-2 and B-3) was smaller than that of the laminated bamboo beam applied with nonprestressed BFRP sheet (specimen B-1). The employment of the prestressed BFRP sheet could increase the load bearing capacity under the same deflection.

6.2.3. Load-Strain Curves. The load-strain curves of the three specimens are shown in Figure 16. The strain data obtained from strain gages $\mathrm{Y}-1$ and $\mathrm{Y}-2$ monitored the strain variation of the top beam surface (compressive state) and from strain gages Y-7 and Y-8 monitored the strain of BFRP sheet (tensile state). As discussed in Section 3.2, the bond between the BFRP sheet and laminated bamboo beam was good enough to view the strain obtained from BFRP sheet as the strain of the bottom surface of the laminated bamboo beam. As seen from Figure 16, the linear strain variation can be observed in all specimens at the initial loading stage. This phenomenon accorded well with the elastic range of the load-deflection curves at the initial stage.

Until the failure point, the maximum compressive and tensile strains of the specimen B-1 applied with nonprestressed BFRP sheet were $-12345 \mu \varepsilon$ and $9649 \mu \varepsilon$, respectively. The maximum compressive strains of specimens B-2 and B-3 applied with prestressed BFRP sheet were respectively $-10007 \mu \varepsilon$ and $-10932 \mu \varepsilon$, and the maximum tensile strains of the two specimens were $7004 \mu \varepsilon$ and $8120 \mu \varepsilon$, respectively. In general, the maximum compressive strain was larger than the maximum tensile strain for all specimens. The failure of all specimens was explained as the tensile strain of the specimen reached the maximum tensile strain. Compared with the laminated bamboo beam applied with non-prestressed BFRP sheet, the ultimate tensile strain of the laminated bamboo beam applied with prestressed
BFRP sheet dropped about $15.8 \%$ to $27.4 \%$. This phenomenon was caused by the existence of the initial tensile strain in the prestressed BFRP sheet.

6.2.4. Strain Distribution along Beam Height and Position of Neutral Axis. The strain distribution along the beam height (captured from strain gages Y-3, Y-4, Y-5, and Y-6) under different loads shown in Figure 17 was analyzed to define the position of the neutral axis. The abscissa of the figure is the measured strain value and the ordinate is the distance between the strain gage and bottom surface of the beam. An almost linear strain distribution along the beam height at the midspan was finally obtained, and the plane section assumption is suitable for the laminated bamboo beam applied by non-prestressed or prestressed BFRP sheet.

Based on the detected strain values in Figure 17, the positions of the neutral axis at the midspan under different loads are calculated in Table 7 . It can be found that the position of the neutral axis was near the middle height of the laminated bamboo beam at the initial loading stage $(5 \mathrm{kN})$. With the further increase of the applied load, the position of the neutral axis gradually went down. Until the ultimate load, the neutral axis of the specimen B-1 was around 0.39 of the laminated bamboo beam height, and the neutral axes of specimens B-2 and B-3 were between 0.43 and 0.44 of the laminated bamboo beam height. It is found that the neutral axis of the laminated bamboo beam applied with prestressed BFRP sheet was a little higher than that of the laminated bamboo beam applied with non-prestressed BFRP sheet under the same load.

\section{Conclusions}

The laminated bamboo beam applied with prestressed BFRP sheet was investigated in this paper. Both prestress loss and flexural performance of the laminated bamboo beam applied with prestressed BFRP sheet were analyzed. Main conclusions are summarized as follows:

(1) A preliminary design of the laminated bamboo beam applied with prestressed BFRP sheet was discussed in this paper, including the reasonable controlled initial prestressed force and prevention of the bond slip. To overcome the deflection resulted from the dead load, the controlled initial prestress is recommended as $55 \%$ of the standard tensile stress of the BFRP sheet, including a $5 \%$ super tension. The bond slip between the BFRP sheet and the laminated bamboo is small and limited with the $100 \mathrm{~mm}$ range away from the loaded end.

(2) Considering the release of the prestressed BFRP sheet, the prestress loss was analyzed according to the specimen preparation stage and specimen storage stage. Based on analyses of prestress loss, the total prestress loss in the preparation stage is recommended as $22.0 \%$, but more calibrated data are required to obtain an acceptable value for the prestress loss in the storage stage due to the diversity of the experimental data. 


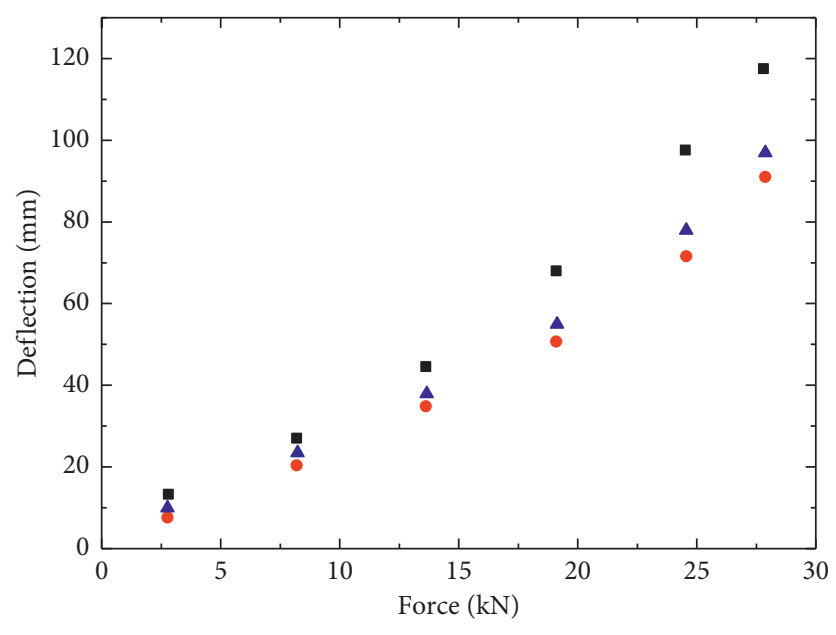

- $\mathrm{B}-1$

- $\mathrm{B}-2$

A $\mathrm{B}-3$

Figure 15: Midspan deflection under levels of loads.

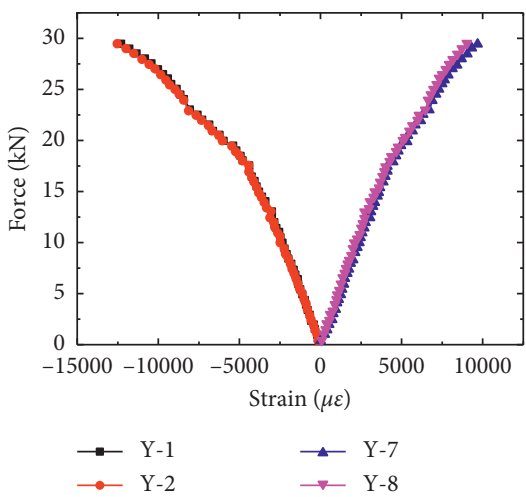

(a)

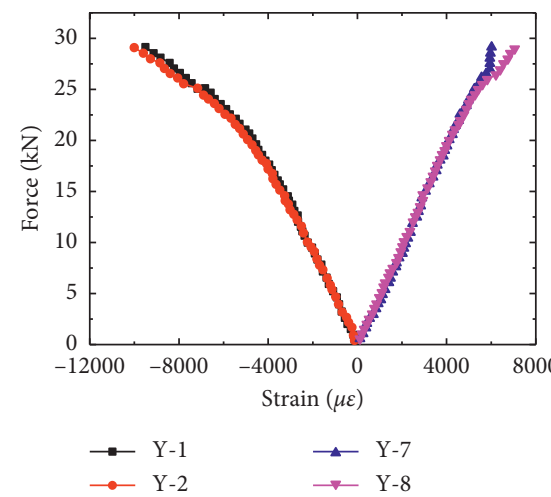

(b)

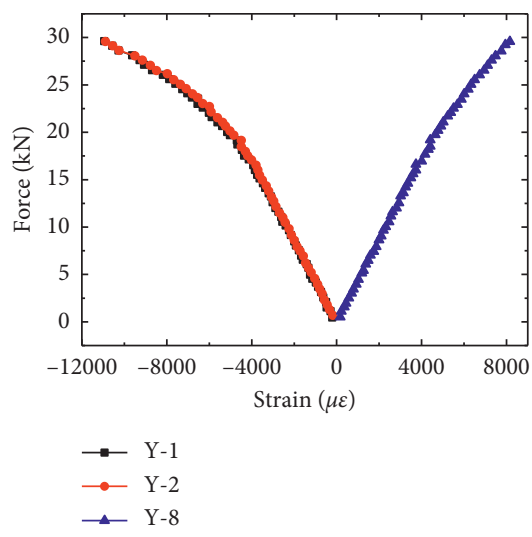

(c)

Figure 16: Load-strain curves of the three specimens: (a) B-1, (b) B-2, and (c) B-3.

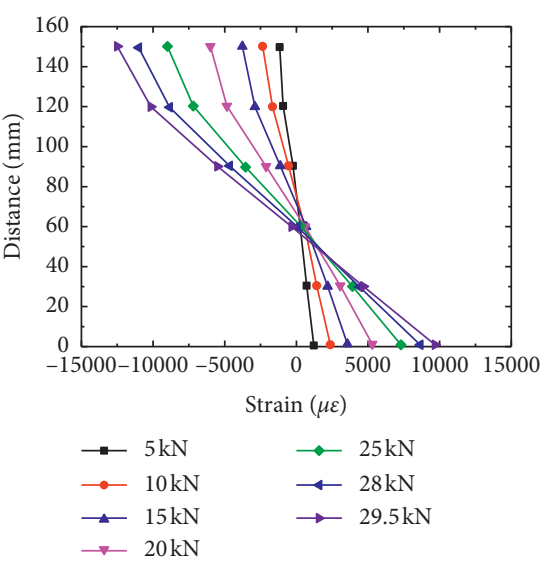

(a)

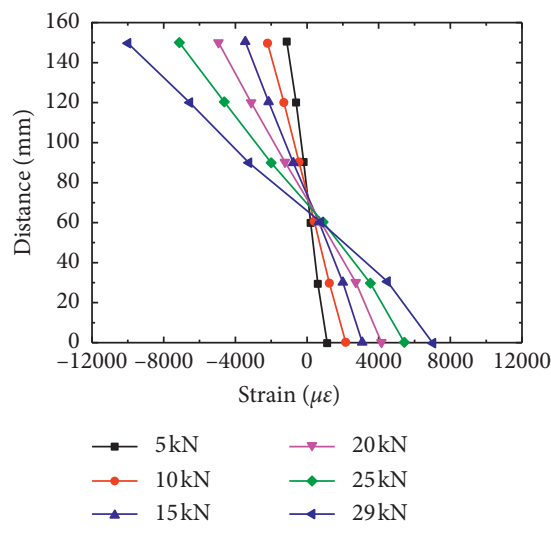

(b)

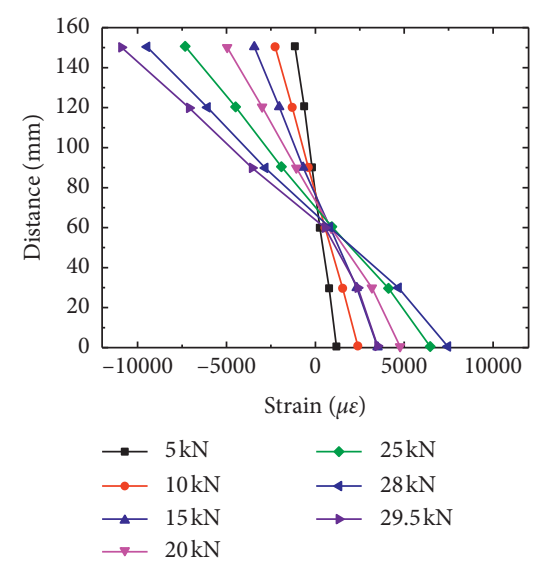

(c)

FIGURE 17: Strain distribution along beam height under different loads: (a) B-1, (b) B-2, and (c) B-3. 
TABle 7: Positions of neutral axis under different loads.

\begin{tabular}{lcccccc}
\hline \multirow{2}{*}{ Load $(\mathrm{kN})$} & \multicolumn{2}{c}{$\mathrm{B}-1$} & \multicolumn{2}{c}{$\mathrm{B}-2$} & \multicolumn{2}{c}{$\mathrm{B}-3$} \\
& $h_{l}(\mathrm{~mm})$ & $h_{l} / h$ & $h_{l}(\mathrm{~mm})$ & $h_{l} / h$ & $h_{l}(\mathrm{~mm})$ & $h_{l} / h$ \\
\hline 5 & 72.97 & 0.49 & 73.90 & 0.49 & 75.26 & 0.50 \\
10 & 72.15 & 0.48 & 73.82 & 0.49 & 75.37 & 0.50 \\
15 & 69.99 & 0.47 & 73.67 & 0.49 & 75.02 & 0.50 \\
20 & 65.82 & 0.44 & 72.05 & 0.48 & 73.62 & 0.49 \\
25 & 61.89 & 0.41 & 68.82 & 0.46 & 69.86 & 0.47 \\
$P_{\mathrm{u}}$ & 57.93 & 0.39 & 65.49 & 0.44 & 63.86 & 0.43 \\
\hline
\end{tabular}

Note. $h_{l}$ is the distance between the neutral axis and the bottom surface of the laminated bamboo beam; $P_{\mathrm{u}}$ is the ultimate load.

(3) The test results of four-point bending showed that the failure of the laminated bamboo beam applied with non-prestressed or prestressed BFRP sheet initiated from the loading point and propagated to a certain distance of the laminated bamboo beam, which can be explained as the tensile strain of the specimen reached the maximum tensile strain.

(4) The ultimate load of the laminated bamboo beam was not affected by the application of the prestressed BFRP sheet, but the ultimate deformation capacity of the laminated bamboo beam applied with prestressed BFRP sheet was reduced compared with that applied with non-prestressed BFRP sheet. The stiffness of the laminated bamboo beam applied with prestressed or non-prestressed BFRP sheet was almost the same in the linear stage, and then after the linear stage, the stiffness of the laminated bamboo beam applied with prestressed BFRP sheet became relatively larger.

(5) The maximum compressive strain was larger than the maximum tensile strain in all specimens. Based on the strain distribution along the beam height, the position of the neutral axis was found to be near the middle height of the beam at the initial loading stage and gradually went down with the increase of the applied load. The neutral axis of the laminated bamboo beam applied with prestressed BFRP sheet finally became higher than that of the laminated bamboo beam applied with non-prestressed BFRP sheet.

\section{Data Availability}

All data used to support the findings of this study are available from the corresponding author upon request.

\section{Conflicts of Interest}

The authors declare that they have no conflicts of interest.

\section{Acknowledgments}

The authors would like to acknowledge financial support from the National Natural Research and Development Fund (9Z05000049D0) and Research and Demonstration
Application of Green Bamboo and Wood Structure System (2017YFC0703502).

\section{References}

[1] S. Amada, Y. Ichikawa, T. Munekata, Y. Nagase, and H. Shimizu, "Fiber texture and mechanical graded structure of bamboo," Composites Part B: Engineering, vol. 28, no. 1-2, pp. 13-20, 1997.

[2] M. Waite, "Sustainable textiles: the role of bamboo and a comparison of bamboo textile properties-Part 1," Journal of Textile and Apparel, Technology and Management, vol. 6, 2009.

[3] T. Afrin, R. K. Kanwar, X. Wang, and T. Tsuzuki, "Properties of bamboo fibres produced using an environmentally benign method," Journal of The Textile Institute, vol. 105, no. 12, pp. 1293-1299, 2014.

[4] C. J. Lee and J. Park, "Growth model of bamboo-shaped carbon nanotubes by thermal chemical vapor deposition," Applied Physics Letters, vol. 77, no. 21, pp. 3397-3399, 2000.

[5] Z. Renjie and Y. Yunshui, Bamboo Based Panel Technology, China Forestry Publishing House, Beijing, China, 2002.

[6] B. Shan, L. Gao, Z. Li, Y. Xiao, and Z. Wang, "Research and applicant of solar energy-prefabricated bamboo pole house," in Proceedings of the the 12th International Symposium on Structural Engineering, Beijing, China, November 2012.

[7] C. Uko and N. Gowripalan, "Strength properties of raffia bamboo," Construction and Building Materials, vol. 3, no. 1, pp. 49-52, 1989.

[8] S. Paudel and M. Lobovikov, "Bamboo housing: market potential for low-income groups," Journal of Bamboo and Rattan, vol. 2, no. 4, pp. 381-396, 2003.

[9] P. J. Kaur, S. Satya, K. K. Pant, and S. N. Naik, "Eco-friendly preservation of bamboo species: traditional to modern techniques,” BioResources, vol. 11, pp. 10604-10624, 2016.

[10] N. Nugroho and N. Ando, "Development of structural composite products made from bamboo II: fundamental properties of laminated bamboo lumber," Journal of Wood Science, vol. 47, no. 3, pp. 237-242, 2001.

[11] M. Mahdavi, P. L. Clouston, and S. R. Arwade, "A lowtechnology approach toward fabrication of laminated bamboo lumber," Construction and Building Materials, vol. 29, pp. 257-262, 2012.

[12] L. Qin and W. Yu, "Research on surface color, properties of thermo-treated reconstituted bamboo lumber after artificial weathering test," Advanced Materials Research, vol. 79-82, pp. 1395-1398, 2009.

[13] Y. W.-jY. Yang-lun and Z. Y. R. Ding-hua, "Studies on factors influencing properties of reconstituted engineering timber made from small-sized bamboo," China Forest Products Industry, vol. 6, p. 7, 2006.

[14] B. Sharma, A. Gatóo, M. Bock, and M. Ramage, "Engineered bamboo for structural applications," Construction and Building Materials, vol. 81, pp. 66-73, 2015.

[15] W. Yang, J. Shenxue, L. Qingfang, Z. Qisheng, W. Libin, and L. Zhitao, "Experimental study on flexural performance of bamboo beams," Building Structure, vol. 1, 2010.

[16] V. De Luca and C. Marano, "Prestressed glulam timbers reinforced with steel bars," Construction and Building Materials, vol. 30, pp. 206-217, 2012.

[17] A. Borri and M. Corradi, "Strengthening of timber beams with high strength steel cords," Composites Part B: Engineering, vol. 42, no. 6, pp. 1480-1491, 2011. 
[18] K. U. Schober and K. Rautenstrauch, "Post-strengthening of timber structures with CFRP's," Materials and Structures, vol. 40, no. 1, pp. 27-35, 2007.

[19] Y. J. Kim and K. A. Harries, "Modeling of timber beams strengthened with various CFRP composites," Engineering Structures, vol. 32, no. 10, pp. 3225-3234, 2010.

[20] S. Ganguly, S. Mondal, P. Das et al., "An insight into the physico-mechanical signatures of silylated graphene oxide in poly (ethylene methyl acrylate) copolymeric thermoplastic matrix," Macromolecular Research, vol. 26, pp. 1-14, 2018.

[21] A. M. Brandt, "Fibre reinforced cement-based (FRC) composites after over 40 years of development in building and civil engineering," Composite Structures, vol. 86, no. 1-3, pp. 3-9, 2008.

[22] S. Ganguly, S. Mondal, P. Das et al., "Design of psyllium-gpoly(acrylicacid-co-sodiumacrylate)/cloisite $10 \mathrm{~A}$ semi-IPN nanocomposite hydrogel and its mechanical, rheological and controlled drug release behaviour," International Journal of Biological Macromolecules, vol. 111, pp. 983-998, 2018.

[23] J. Peterson, "Wood beams prestressed with bonded tension elements," Journal of the Structural Division, vol. 91, pp. 103-120, 1965.

[24] P. Banibayat and A. Patnaik, "Variability of mechanical properties of basalt fiber reinforced polymer bars manufactured by wet-layup method," Materials and Design, vol. 56, pp. 898-906, 2014.

[25] C. Gentile, D. Svecova, and S. H. Rizkalla, "Timber beams strengthened with GFRP bars: development and applications," Journal of Composites for Construction, vol. 6, no. 1, pp. 11-20, 2002.

[26] Y. Wei, X. Ji, M. Duan, and G. Li, "Flexural performance of bamboo scrimber beams strengthened with fiber-reinforced polymer," Construction and Building Materials, vol. 142, pp. 66-82, 2017.

[27] W.-W. Wang, J.-G. Dai, K. A. Harries, and Q.-H. Bao, "Prestress losses and flexural behavior of reinforced concrete beams strengthened with posttensioned CFRP sheets," Journal of Composites for Construction, vol. 16, no. 2, pp. 207-216, 2011.

[28] H. Diab, Z. Wu, and K. Iwashita, "Short and long-term bond performance of prestressed FRP sheet anchorages," Engineering Structures, vol. 31, no. 5, pp. 1241-1249, 2009.

[29] R-02 A, Guide for the Design and Construction of Externally Bonded FRP Systems for Strengthening Concrete Structures, American Concrete Institute, Farmington Hills, MI, USA, 2003.

[30] Q. Lv, Y. Liu, and Y. Ding, "Study on bond behaviors between BFRP bar/sheet and bamboo engineering materials," $A d$ vances in Structural Engineering, 2019.

[31] F. Bencardino, G. Spadea, and R. N. Swamy, "Strength and ductility of reinforced concrete beams externally reinforced with carbon fiber fabric," Structural Journal, vol. 99, no. 2, pp. 163-171, 2002.

[32] H. N. Garden and L. C. Hollaway, "An experimental study of the influence of plate end anchorage of carbon fibre composite plates used to strengthen reinforced concrete beams," Composite Structures, vol. 42, no. 2, pp. 175-188, 1998. 


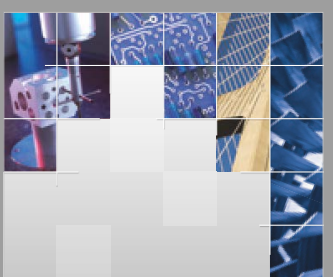

\section{Enfincering}
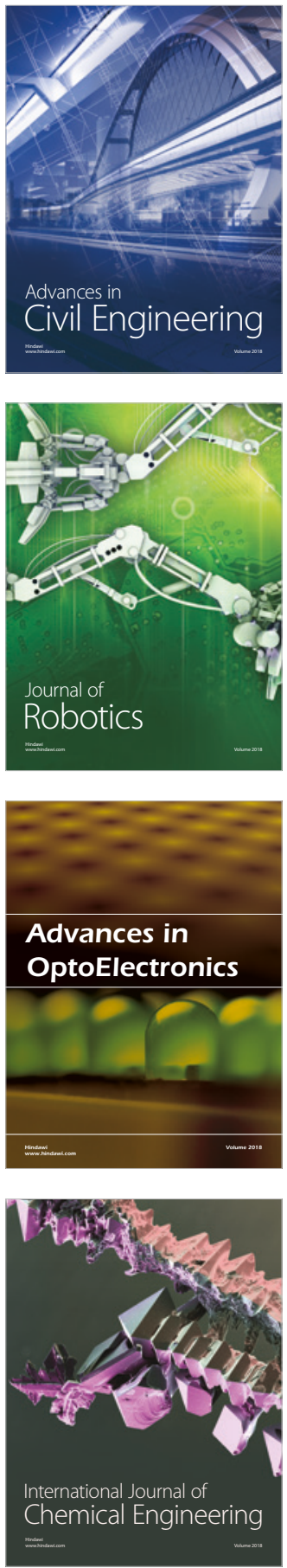

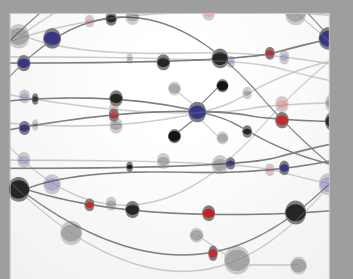

\section{Rotating \\ Machinery}

The Scientific World Journal

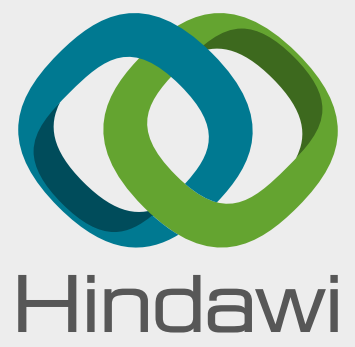

Submit your manuscripts at

www.hindawi.com
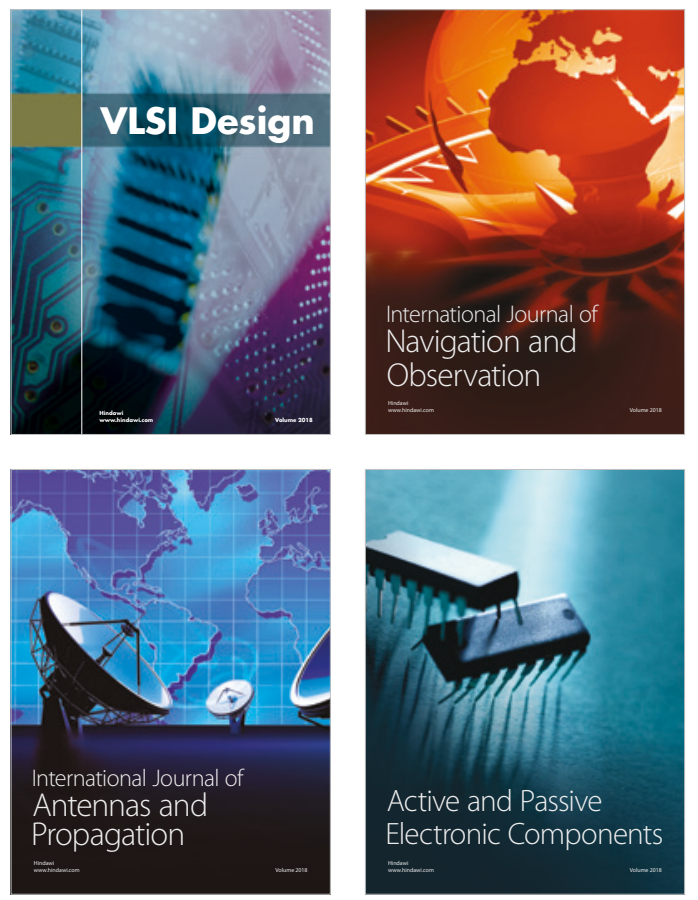
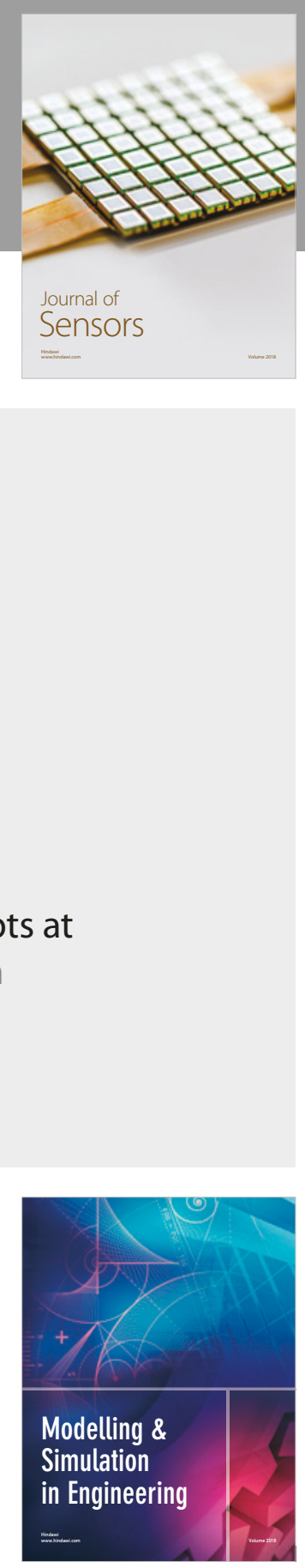

\section{Advances \\ Multimedia}
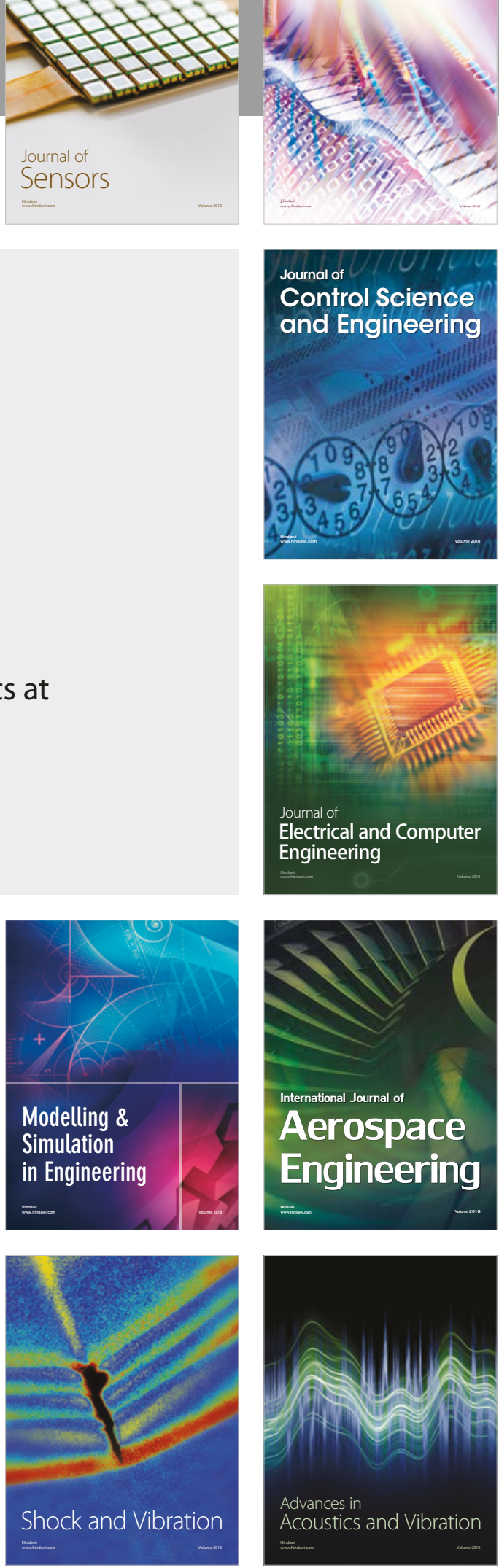